\title{
Crystallite Size Analysis of Pressure-Crystallized Polyethylene by Nitric Acid Etching and Gel-Permeation Chromatography. II. Folded-Chain Crystals and Ordinary Extended-Chain Crystals
}

\author{
Yoji MAEDA and Hisaaki KANETSUNA \\ Research Institute for Polymers and Textiles, \\ 1-1-4, Yatabe-Higashi, Tsukuba, Ibaraki 305, Japan.
}

(Received August 28, 1980)

\begin{abstract}
Statistical analysis of average lamellar thickness and its size distribution in the molecular chain direction has been made on a variety of folded-chain crystals and ordinary extended-chain crystals of linear polyethylene which were crystallized under high pressures of 106 $\mathrm{MPa}$ and $305 \mathrm{MPa}$. This was done by fuming nitric acid degradation followed by gel-permeation chromatography (GPC) measurement of molecular weight distribution of the degraded samples. The observed GPC curves were corrected for instrumental spreading using the Chang-Huang's method of correction. Several new experimental facts became.clear. First, the existence of folds was confirmed in the ordinary extended-chain crystals formed at $305 \mathrm{MPa}$. Second, the average lamellar thickness of the defect-free crystalline core of folded-chain crystals was often found to be approximately one tenth the average thickness of ordinary extended-chain crystals in the same sample. Third, in ordinary extended-chain crystals with average lamellar thicknesses of several hundred nanometers, it was observed that the average crystal thickness decreased markedly with increasing degradation time, compared with the folded-chain crystals and that the chain-thinning effect tended to be become greater with an increase in average crystal thiçkness. This suggests strongly that ordinary extended-chain crystals have surface structures easily accessible to nitric acid etching. Since the crystal thickness of ordinary extended-chain crystals is comparable to the number-average molecular weight of the original material, crystalline lamellae will be terminated predominantly in the form of extended-chains. It may be reasonable to assume extended-chain crystals with gradually disordered, long surface layers from about 20 to 50 nanometers as a possible model for ordinary extended-chain crystals.
\end{abstract}

KEY WORDS Polyethylene / High-Pressure Crystallization / Nitric Acid Etching / Gel-Permeation Chromatography / Instrumental Spreading Correction / Average Crystal Thickness / Crystallite Size Distribution / Folded- Chain Crystals / Ordinary Extended-Chain Crystals /

Previous paper ${ }^{1}$ presented the details of the effect of fuming nitric acid etching on extended-chain crystals (ECC) of linear polyethylene crystallized from the melt under about $500 \mathrm{MPa}$. The purpose of this paper is a continuation of the study on folded-chain crystals (FCC) and ordinary ECC of the same polyethylene. Crystallization was carried out under high pressures of about $100 \mathrm{MPa}$ and 300 $\mathrm{MPa}$. Information on morphology of FCC and ordinary ECC formed under pressures has accumulated up to the present, but information on lamellar thickness distribution and the surface structure of these crystals has scarcely been obtained as a result of there being no satisfactory methods for measuring crystal thickness greater than $100 \mathrm{~nm}$ and size distribution. Of course such dimensions are beyond the limits of resolution of most small angle X-ray scattering methods. One of the most useful approaches to this problem is selective chemical degradation by strong oxidizing agents. In this study, we deal with a quantitative analysis of molecular chain extension of crystalline lamellae and size distribution of polyethylene crystals formed under high pressures by the specific method of 
fuming nitric acid degradation followed by measuring the molecular weight distribution (MWD) of the degraded samples with gel-permeation chromatograph (GPC).

\section{EXPERIMENTAL}

\section{Materials and Methods of Investigation}

The material used in this study was Sholex S 6002, a linear polyethylene with a weight-average molecular weight $M_{w}$ of 165,000 and a polydispersity $M_{w} / M_{n}$ of 5.2; it was supplied by Showa Denko Co. Samples were crystallized from the melt under high pressures of $106 \mathrm{MPa}$ and $305 \mathrm{MPa}$, in the high pressure dilatometer described in detail elsewhere. ${ }^{2}$ The conditions used in the fuming nitric acid treatment and GPC measurement are identical with those described in the preceding paper. ${ }^{1}$ The GPC curves of the degraded samples were obtained by a Waters Inc., model 200 gel-permeation chromatograph (GPC). Molecular weight (MW) of polyethylene was estimated within about $13 \%$, using the universal calibration. ${ }^{1}$ The observed GPC curves were corrected for instrumental spreading by Chang-Huang's correction method. ${ }^{3}$

\section{RESULTS}

Figure 1 shows the DSC curves of the two samples crystallized at $423 \mathrm{~K}$ and $434 \mathrm{~K}$ for $20 \mathrm{~h}$ under a high pressure of $106 \mathrm{MPa}$. It is well known that the sample formed at low pressures below 200 $\mathrm{MPa}$ is composed of FCC. The DSC curve of the sample formed at $423 \mathrm{~K}$ shows a single endothermic peak of fusion at $408.2 \mathrm{~K}$. The DSC curve of the sample formed at $434 \mathrm{~K}$ shows two endothermic peaks of fusion at $407.1 \mathrm{~K}$ and $411.3 \mathrm{~K}$, and indicates the fusion of two kinds of FCC having different melting points. We refer to those as thin FCC and thick FCC. The DSC curve of the sample cooled from the melt shows a single melting peak at $408.1 \mathrm{~K}$ and has the same pattern as that of the sample formed at $423 \mathrm{~K}$. Figures 2, 3, and 7 show the variation in the GPC curves of these samples during the course of nitric acid degradation. The GPC curves of the two samples formed at $423 \mathrm{~K}$ and by cooling from the melt showed the same striking features as those of the degraded single crystals ${ }^{4}$ and the bulk samples ${ }^{5,6}$ of polyethylene: multiple peaks are present and the lowest MW peak grows at the

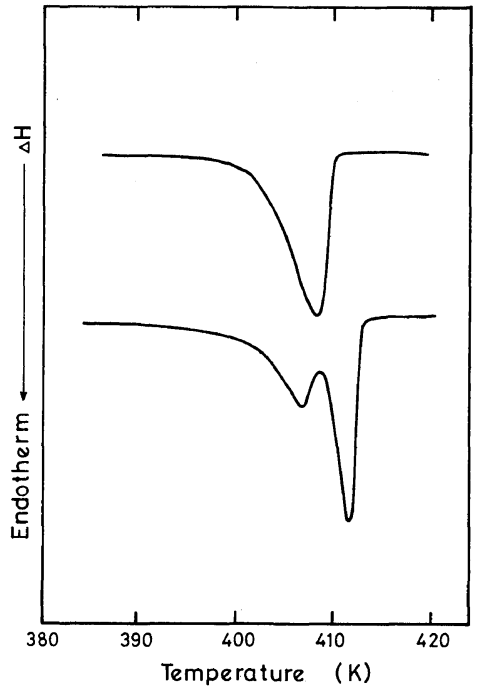

Figure 1. Differential scanning ealorimetry (DSC) melting curves of samples crystallized at $423 \mathrm{~K}$ (top) and $434 \mathrm{~K}$ (bottom) under $106 \mathrm{MPa}$ : heating rate, $5 \mathrm{~K} \mathrm{~min}^{-1}$.

expense of higher MW materials with degradation time, until it alone remains. The strong peak at the larger elution volume (or at the lower MW) in Figure 2 and Figure 7 grew with increasing degradation time, and it was the only one that remained during the oxidation for $48 \mathrm{~h}$. It is clear that this final remaining peak corresponds to the single chain traverse length through the crystalline core of the folded-chain lamellae. Another peak at a smaller elution volume (or a higher $\mathrm{MW}$ ) which appeared in the initial and intermediate stages of oxidation, decreased with time, and then reduced markedly or disappeared. Since the ratio of the peak chain lengths between the observed two GPC peaks varied from 2.60 to 2.04 with degradation time, the peak at the smaller elution volume is attributable to the second-order peak which corresponds to the double-chain traverse length of the FCC. The GPC curves were corrected for instrumental spreading and its was then found that the peak at the smaller elution volume contained another higher-order peak that was 5 times the chain traverse length of the FCC. Furthermore, a higher-order peak that was from 9 to 10 times the chain length of the FCC could be seen slightly, but no further observation of this peak was attempted owing to poor resolution. On the other hand, a small peak was observed in the lowest MW region at the initial and intermediate 


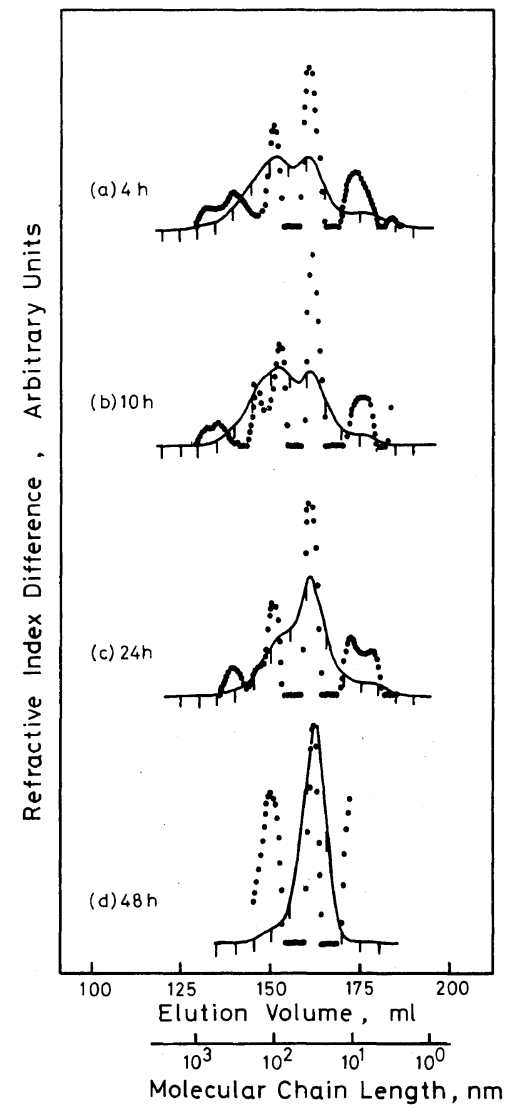

Figure 2. GPC curves of sample formed at $423 \mathrm{~K}$ and $106 \mathrm{MPa}$ followed by degradation with nitric acid for (a) $4 \mathrm{~h}$, (b) $10 \mathrm{~h}$, (c) $24 \mathrm{~h}$, and (d) $48 \mathrm{~h}$.

stages of oxidation. This small peak was situated at a MW of about 1,000. This peak disappeared during the $48 \mathrm{~h}$ degradation. The general behavior of the GPC curves was also observed for the sample cooled from the melt in Figure 7. The observed GPC curves of the sample formed at $434 \mathrm{~K}$ showed an interesting distribution pattern with the three strong peaks shown in Figure 3. The GPC peak at the smallest elution volume decreased markedly with time, while the other two peaks grew to constant levels respectively. Since the whole distribution pattern of the GPC curve for the sample degraded for $72 \mathrm{~h}$ corresponded well to the DSC melting pattern of the original sample, the strongest GPC peak at the intermediate volume and the peak at the largest volume may be attributed to the MWDs corresponding to the lamellar thickness distributions of

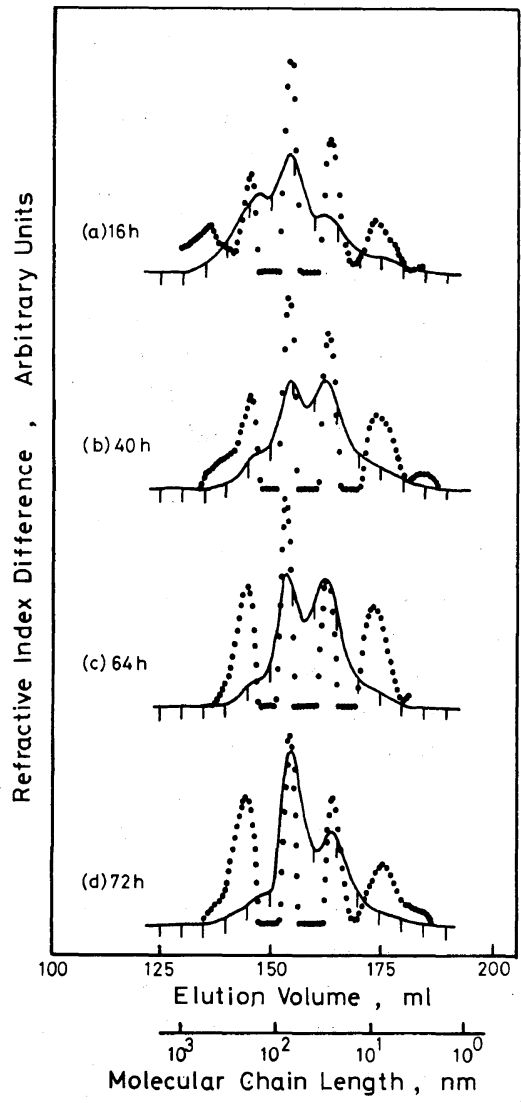

Figure 3. GPC curves of sample formed at $434 \mathrm{~K}$ and $106 \mathrm{MPa}$ and then degraded with fuming nitric acid for (a) $16 \mathrm{~h}$, (b) $40 \mathrm{~h}$, (c) $64 \mathrm{~h}$, and (d) $72 \mathrm{~h}$.

the thick FCC and thin FCC, respectively. The decreasing peak at the smallest volume was attributed to the second-order peak corresponding to the double traverse length of the thick FCC since the ratio of the peak chain lengths between the decreasing peak and the strongest peak was between 2.20 and 2.40. The second-order peak of the thick FCC remained to a small extent even after the thorough degradation of $72 \mathrm{~h}$. At the same time, the GPC peak at the largest elution volume corresponding to the chain length of the thin FCC tailed toward lower MW in all stages of the oxidation. The shoulder was corrected as an independent MWD peak with an average MW of $1,400-1,700$ on the corrected GPC curves.

Peak position is expressed in terms of chain length through an appropriate calibration curve. If the 
chain inclination against the crystal surfaces may be neglected, then the peak chain length is directly attributable to the average lamellar thickness of degraded crystal. The average lamellar thickness of the FCC crystallized at $423 \mathrm{~K}$ and then degraded for $48 \mathrm{~h}$ was estimated to be $33.5 \mathrm{~nm}$ on the corrected GPC curve in Figure 2. The crystal thickness was the length of defect-free crystalline core in which the amorphous layers and folds were cut almost completely and then removed. The average lamellar thicknesses of the thick FCC and thin FCC in the sample crystallized at $434 \mathrm{~K}$ and then degraded for $72 \mathrm{~h}$ were estimated to be $90 \mathrm{~nm}$ and $36 \mathrm{~nm}$ respectively on the corrected GPC curve in Figure 3. Figure 4 shows the relation of the peak chain lengths of the FCC crystals in the two samples as a function of degradation time. The average lamellar thickness of original crystal can be estimated by extrapolation to zero degradation time. The origial thickness of the FCC crystallized at $423 \mathrm{~K}$ was extrapolated to be $38 \mathrm{~nm}$, and the original crystal thicknesses of the thick FCC and thin FCC were extrapolated to be $92 \mathrm{~nm}$ and $39 \mathrm{~nm}$, respectively.

Figure 5 shows the degradation time dependence of the corrected MWD curves corresponding to the crystal thickness distribution of the FCC crystallized at $423 \mathrm{~K}$. During the period of oxidation for $48 \mathrm{~h}$, the narrowing of the distribution was more than $1.8 \mathrm{~nm}$ in the highest $\mathrm{MW}$ end and more than

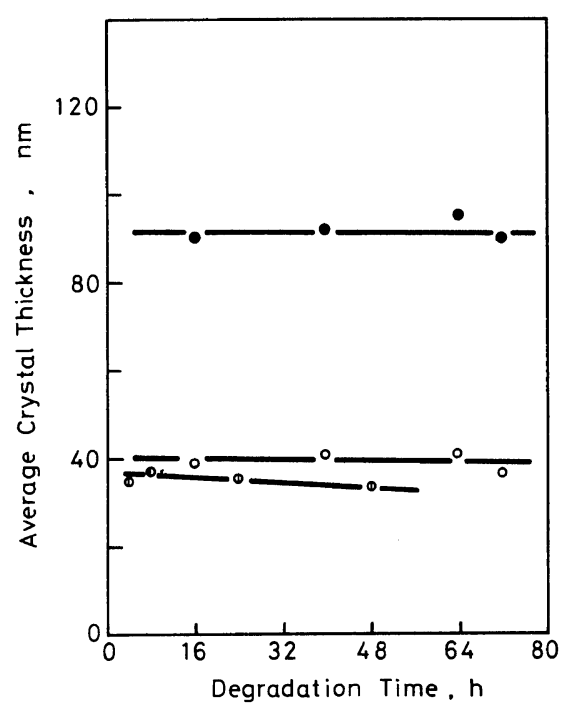

Figure 4. Variation in average crystal thicknesses of FCC (1) formed at $423 \mathrm{~K}$, thick FCC (O) and thin FCC (O) formed at $434 \mathrm{~K}$ with degradation time.

$4 \mathrm{~nm}$ in the lowest MW end. The MWD curve of the FCC degraded for $48 \mathrm{~h}$ indicated a lamellar thickness distribution from $26 \mathrm{~nm}$ to $45 \mathrm{~nm}$ with an average lamellar thickness of $33.5 \mathrm{~nm}$ and showed the size distribution of a defect-fee crystalline core of the FCC. Figure 6 shows the degradation time dependence of the two corrected MWD curves for

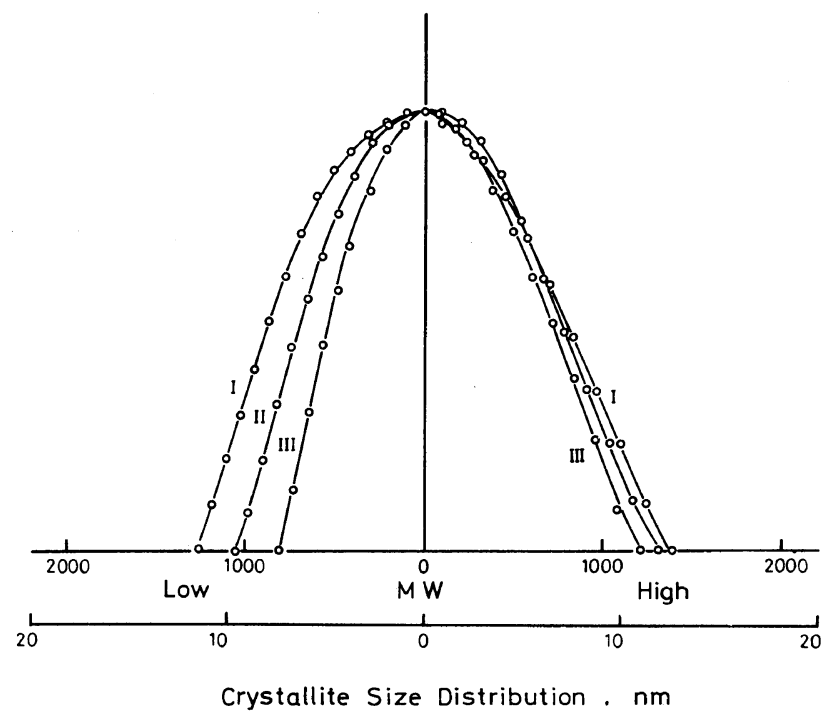

Figure 5. Degradation time dependence of MWD corresponding to the lamellar thickness distribution of the FCC formed at $423 \mathrm{~K}$ : I, $10 \mathrm{~h}$; II, $24 \mathrm{~h}$; III, $48 \mathrm{~h}$. 


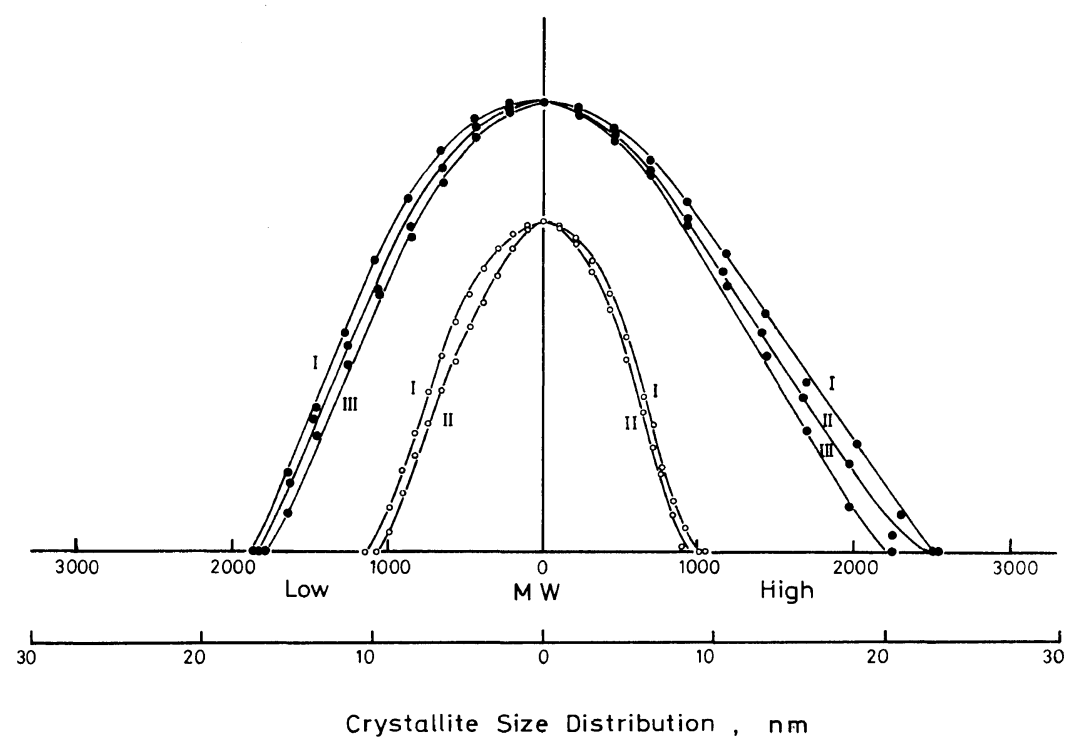

Figure 6. Degradation time dependence of MWDs corresponding to the lammellar thickness distributions of thick FCC (O) and thin FCC (O) in the sample formed at $434 \mathrm{~K}: \mathrm{I}, 40 \mathrm{~h}$; II, $64 \mathrm{~h}$; III, $72 \mathrm{~h}$.

the thick FCC and thin FCC in the sample crystallized at $434 \mathrm{~K}$. The whole distribution of MWD of the thick FCC was found to be approximately twice the MWD of the thin FCC. During the period of oxidation for $72 \mathrm{~h}$, the MWD curve of the thick FCC narrowed to moe than $4 \mathrm{~nm}$ in the highest $\mathrm{MW}$ end and to more than $1 \mathrm{~nm}$ in the lowest MW end. The corrected MWD curve of the thick FCC degraded for $72 \mathrm{~h}$ indicated that the crystal lamellae were distributed from $73 \mathrm{~nm}$ to $110 \mathrm{~nm}$ with an average lamellar thickness of $90 \mathrm{~nm}$. But there being no disappearance of the secondorder peak for the thick FCC suggests that some folds still remained in the crystal degraded for $72 \mathrm{~h}$. The MWD of the thin FCC is comparable to that of the FCC crystallized at $423 \mathrm{~K}$.

It is well known that polyethylene crystallized from the melt under pressures between $200 \mathrm{MPa}$ and $350 \mathrm{MPa}$ consists of FCC and ordinary ECC, and that ordinary ECC grows with increasing crystallization pressure and temperature. Figure 8 shows the DSC curves of samples crystallized at various temperatures under a high pressure of $305 \mathrm{MPa}$. FCC is produced only in the sample formed at $433 \mathrm{~K}$. The DSC curve of the sample formed at $458 \mathrm{~K}$ showed the fusion of FCC and ordinary ECC at its melting points at $406.4 \mathrm{~K}$ and $411.3 \mathrm{~K}$. The melting peak of the ordinary ECC grew into a main peak with increasing crystallization temperature. Finally the sample formed at $473 \mathrm{~K}$ showed triple endothermic peaks at $407.2 \mathrm{~K}, 411.8 \mathrm{~K}$, and $415.5 \mathrm{~K}$, indicating the fusion of thin FCC, thick FCC, and ordinary ECC, respectively. Figure 9 shows the variation in the GPC curves of the sample formed at $458 \mathrm{~K}$ in the course of oxidation. The GPC peak at a larger elution volume grew sharply with degradation time, while the peak at a smaller elution volume decreased to a constant level. Since the whole MWD pattern of the GPC curve degraded for $48 \mathrm{~h}$ corresponded well to the DSC melting pattern of the original sample, the two GPC peaks at larger and smaller elution volumes are attributable to the MWDs of the lamellar thickness distribution of FCC and ordinary ECC, respectively. The cause for the decrease in the GPC peak of the ordinary ECC can be explained as due to the decrease in the overlapping contribution of the uncut chains of both FCC and ordinary ECC. The corrected GPC curves indicated two other higherorder peaks corresponding to twice and quadruple the chain length of the ordinary ECC. On the other hand, a small peak with a MW of about 1,600 could always be observed in the lowest MW region and it remained even after $48 \mathrm{~h}$. Figure 10 shows the relation of the average lamellar thicknesses of the FCC and the ordinary ECC to degradation time. 


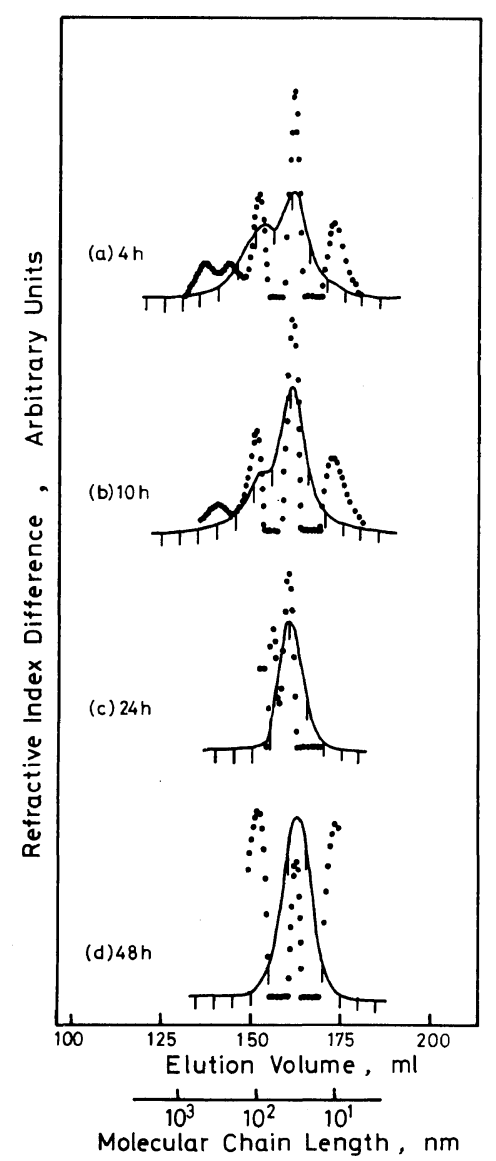

Figure 7. GPC curves of sample cooled from the melt at $106 \mathrm{MPa}$ and then degraded with fuming nitric acid for (a) $4 \mathrm{~h}$, (b) $10 \mathrm{~h}$, (c) $24 \mathrm{~h}$, and (d) $48 \mathrm{~h}$.

The average lamellar thickness of the original crystals of ordinary ECC and FCC were extrapolated to be $103 \mathrm{~nm}$ and $44 \mathrm{~nm}$, respectively.

Figure 11 shows the variation in the GPC curves of the sample crystallized at $468 \mathrm{~K}$ during oxidation. The DSC curve of the original sample showed a main peak and a shoulder at $412.8 \mathrm{~K}$ and $410.6 \mathrm{~K}$, besides a small, low-temperature peak at about $401 \mathrm{~K}$. This indicates that the sample is composed mainly of ordinary ECC and thick FCC in addition to small amounts of metastable thin FCC. The observed GPC curves became clearer with increasing degradation time. The GPC curves of the samples degraded for $24 \mathrm{~h}$ and $48 \mathrm{~h}$ showed two strong GPC peaks, corresponding to the DSC melting pattern of the original sample. Accordingly,

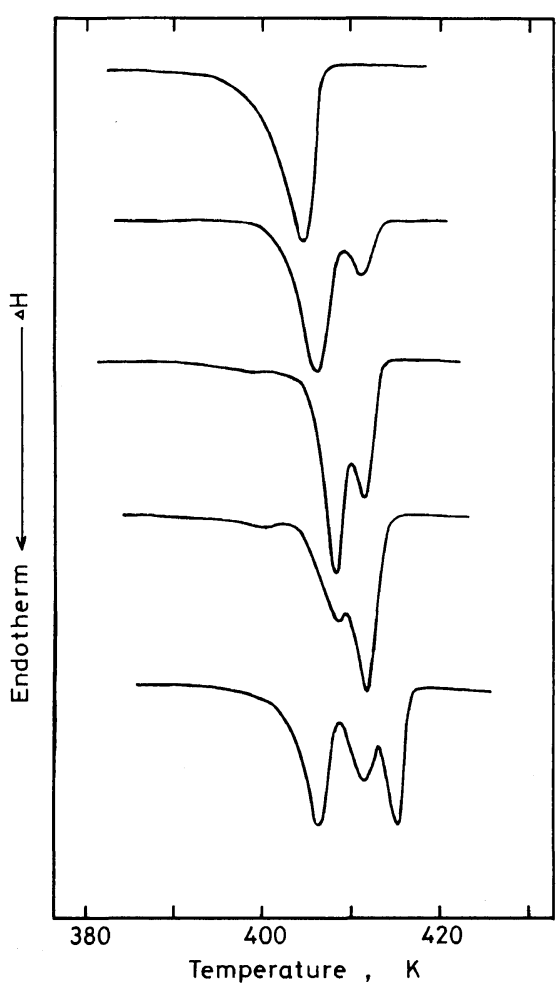

Figure 8. DSC melting curves of samples crystallized at $305 \mathrm{MPa}$ under the following conditions (from top to bottom): $433 \mathrm{~K}$ for $2 \mathrm{~h}, 458 \mathrm{~K}$ for $20 \mathrm{~h}, 463 \mathrm{~K}$ for $20 \mathrm{~h}$, $468 \mathrm{~K}$ for $20 \mathrm{~h}$, and $473 \mathrm{~K}$ for $20 \mathrm{~h}$; heating rate, $5 \mathrm{~K}$ $\min ^{-1}$.

the two GPC peaks and a shoulder at the lower MW region were attributed to the MWDs corresponding to the lamellar thickness distributions of ordinary ECC, thick FCC, and thin FCC, in the order of increasing elution volume, respectively. The corrected GPC curves suggest that the GPC peak at a smaller volume of the ordinary ECC also contain two other higher-order peaks corresponding to 2.5 times and quadruple the chain length of ordinary ECC. Figure 12 shows the relation of the average lamellar thicknesses of ordinary ECC, thick FCC, and thin FCC to degradation time. It is noteworthy that the lamellar thickness of ordinary ECC decreased markedly with degradation time. The average lamellar thicknesses of these original crystals were extrapolated to be $240 \mathrm{~nm}, 93 \mathrm{~nm}$, and $36 \mathrm{~nm}$, respectively.

Figure 13 shows the variation in the GPC curves of the sample crystallized at $473 \mathrm{~K}$ in the course of 


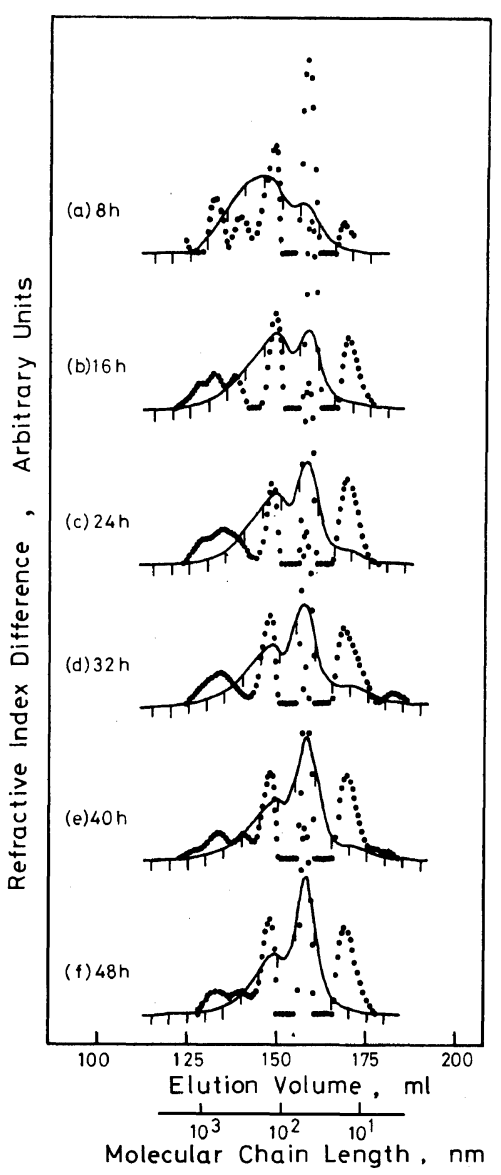

Figure 9. GPC curves of sample formed at $458 \mathrm{~K}$ and $305 \mathrm{MPa}$ and then degraded with fuming nitric acid for (a) $8 \mathrm{~h}$, (b) $16 \mathrm{~h}$, (c) $24 \mathrm{~h}$, (d) $32 \mathrm{~h}$, (3) $40 \mathrm{~h}$, and (f) $48 \mathrm{~h}$.

oxidation. The DSC curve of the original sample showed an interesting melting pattern of comparable peaks of ordinary ECC, thick FCC, and thin FCC. Since the observed GPC curve of the sample degraded for $48 \mathrm{~h}$ corresponded well to the melting pattern, the three GPC peaks may be attributed to the MWDs having the lamellar thickness distribution of ordinary ECC, thick FCC, and thin FCC in the order of increasing elution volume. Also on the GPC curves, a shoulder could always be observed in the lowest MW region and corresponded to a MW of about 1,600-2,000, and remained even after the degradation of $48 \mathrm{~h}$. Figure 14 shows the relation of the average lamellar thicknesses of these three crystals to degradation time. The original lamellar thicknesses of ordinary

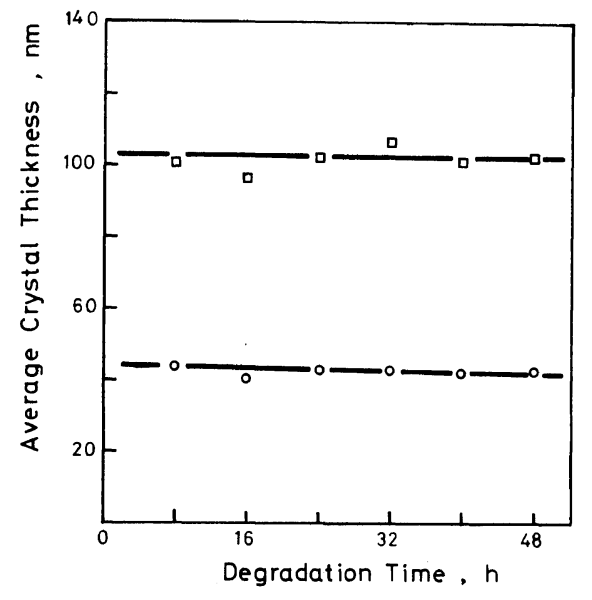

Figure 10. Variation in average crystal thicknesses of ordinary ECC ( $\square)$ and FCC ( $\bigcirc)$ with degradation time. Crystallization was carried out at $458 \mathrm{~K}$ under $305 \mathrm{MPa}$.

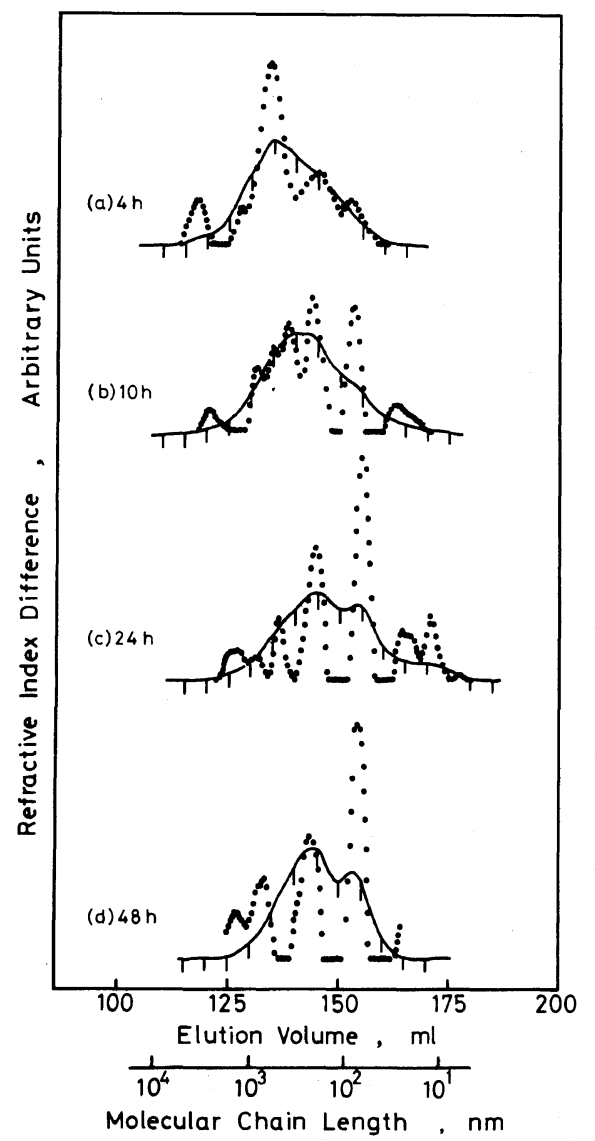

Figure 11. GPC curves of sample formed at $468 \mathrm{~K}$ and $305 \mathrm{MPa}$ and then degraded with fuming nitric acid for (a) $4 \mathrm{~h}$, (b) $10 \mathrm{~h}$, (c) $24 \mathrm{~h}$, and (d) $48 \mathrm{~h}$. 


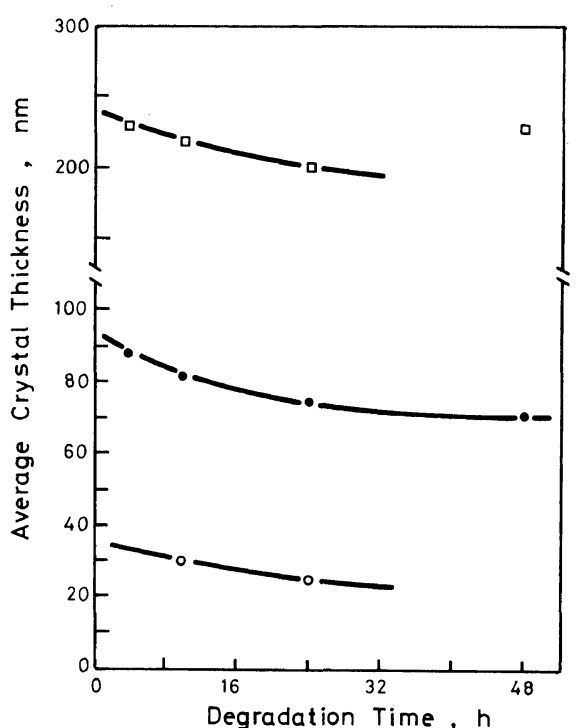

Figure 12. Variation in average crystal thicknesses of ordinary ECC $(\square)$, thick FCC ( $)$, and thin FCC (O) with degradation time. Crystallization was carried out at $468 \mathrm{~K}$ and $305 \mathrm{MPa}$.

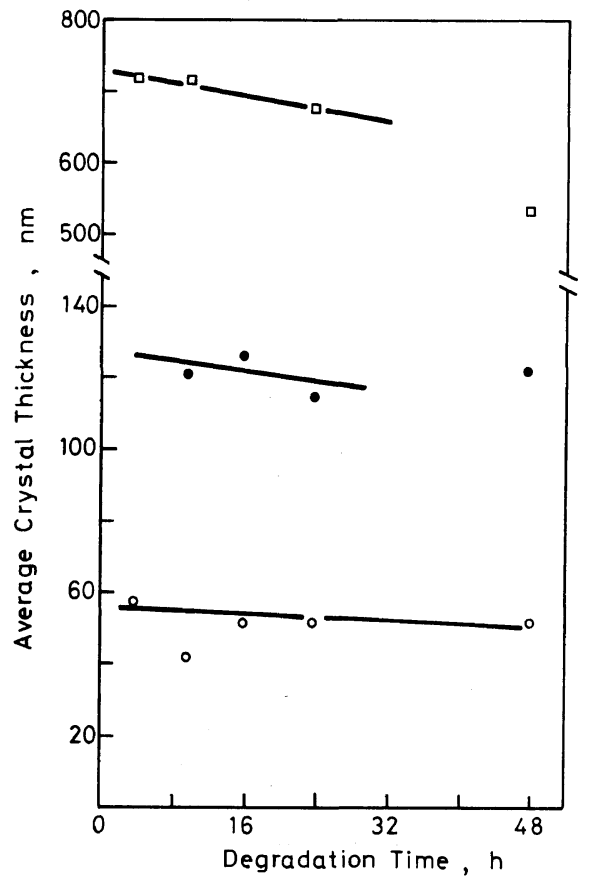

Figure 14. Variation in average crystal thicknesses of ordinary ECC $(\square)$, thick FCC (๑), and thin FCC (O) with degradation time. Crystallization was carried out at $473 \mathrm{~K}$ and $305 \mathrm{MPa}$.

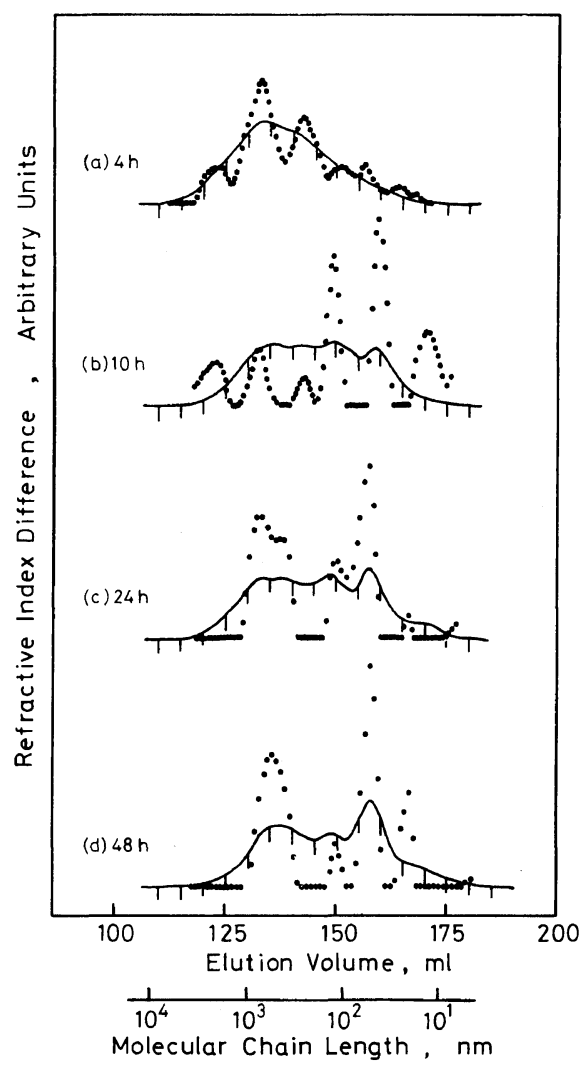

Figure 13. GPC curves of sample formed at $473 \mathrm{~K}$ and $305 \mathrm{MPa}$ and then degraded with fuming nitric acid for (a) $4 \mathrm{~h}$, (b) $10 \mathrm{~h}$, (c) $24 \mathrm{~h}$, and (d) $48 \mathrm{~h}$.

ECC, thick FCC, and thin FCC were extrapolated to be $730 \mathrm{~nm}, 121 \mathrm{~nm}$, and $58 \mathrm{~nm}$, respectively. Also, in this case, the lamellar thickness of ordinary ECC decreased markedly with degradation time.

Figure 15 shows the temperature dependence of the average lamellar thicknesses of ordinary ECC, thick FCC, and thin FCC in various samples crystallized under $305 \mathrm{MPa}$ and then were degraded for $48 \mathrm{~h}$. Ordinary ECC formed at $453 \mathrm{~K}$ had only an average lamellar thickness of about $100 \mathrm{~nm}$, but the crystal thickness increased sharply to about $700 \mathrm{~nm}$ with increasing crystalization temperature. On the other hand, the lamellar thickness of FCC increased gradually with temperature. In a higher temperature region above $463 \mathrm{~K}$, the lamellar thickness of thick FCC increased from $43 \mathrm{~nm}$ to $122 \mathrm{~nm}$ and the thickness of thin FCC also increased from $25 \mathrm{~nm}$ to $52 \mathrm{~nm}$. Figure 16 shows the variation in the GPC curves of the sample cooled from the 


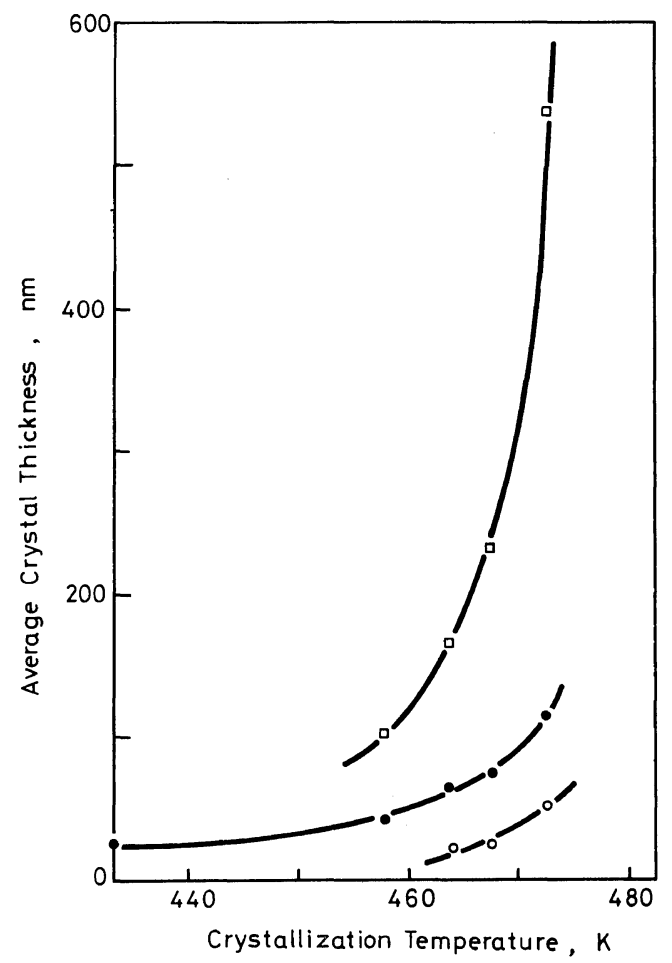

Figure 15. Temperature dependence of average crystal thicknesses of ordinary ECC ( $\square)$, thick FCC (๑), and thin FCC $(O)$.

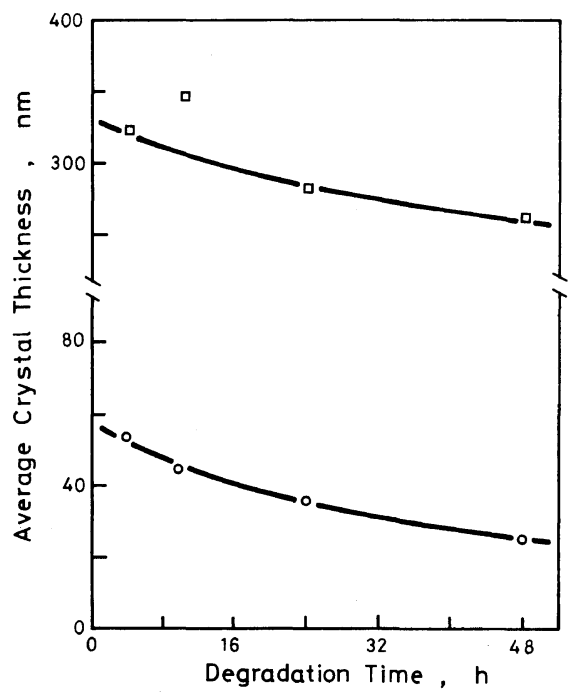

Figure 17. Variation in average crystal thicknesses of ordinary ECC $(\square)$ and FCC (O) with degradation time. These crystals were formed by cooling from the melt at $305 \mathrm{MPa}$.

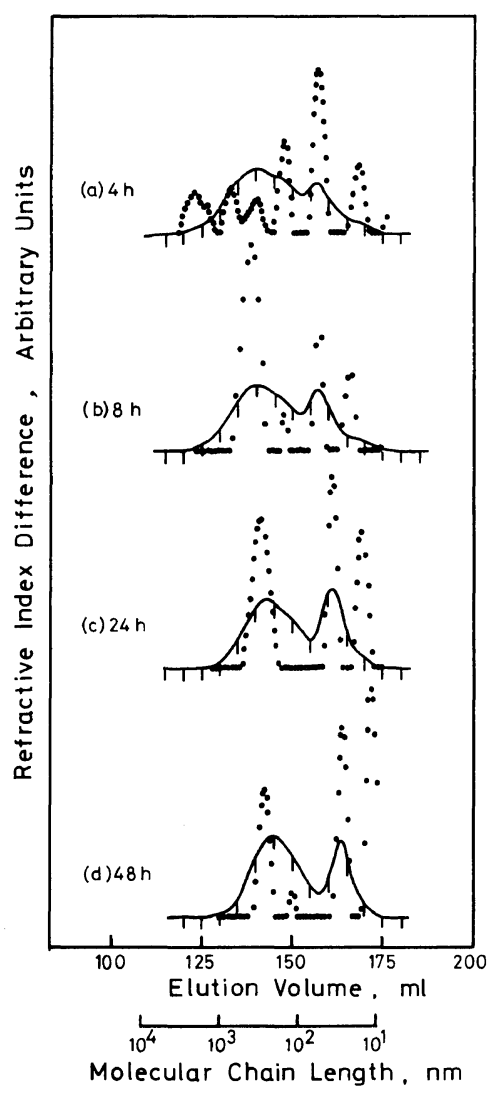

Figure 16. GPC curves of sample cooled from the melt at $305 \mathrm{MPa}$ and then degraded with fuming nitric acid for (a) $4 \mathrm{~h}$, (b) $8 \mathrm{~h}$, (c) $24 \mathrm{~h}$, and (d) $48 \mathrm{~h}$.

melt in the course of oxidation. The DSC curve of the original sample showed a melting pattern typical of FCC and ordinary ECC, with comparable peaks at $405.7 \mathrm{~K}$ and $412.3 \mathrm{~K}$. The observed GPC curves of the samples degraded for $24 \mathrm{~h}$ and $48 \mathrm{~h}$ clearly showed two comparable GPC peaks, a broad peak at a smaller elution volume and a sharp peak at a larger elution volume. These peaks are attributable to MWDs having the lamellar thickness distribution of ordinary ECC and FCC, respectively. The average lamellar thicknesses of ordinary ECC and FCC degraded for $48 \mathrm{~h}$ were estimated to be $262 \mathrm{~nm}$ and $26 \mathrm{~nm}$, respectively. Figure 17 shows the relation of the average lamellar thicknesses of the two crystals to degradation time. The average crystal thicknesses of the original ordinary ECC and the original FCC were extrapolated to be $335 \mathrm{~nm}$ and $57 \mathrm{~nm}$, respectively. It is very interesting to note 


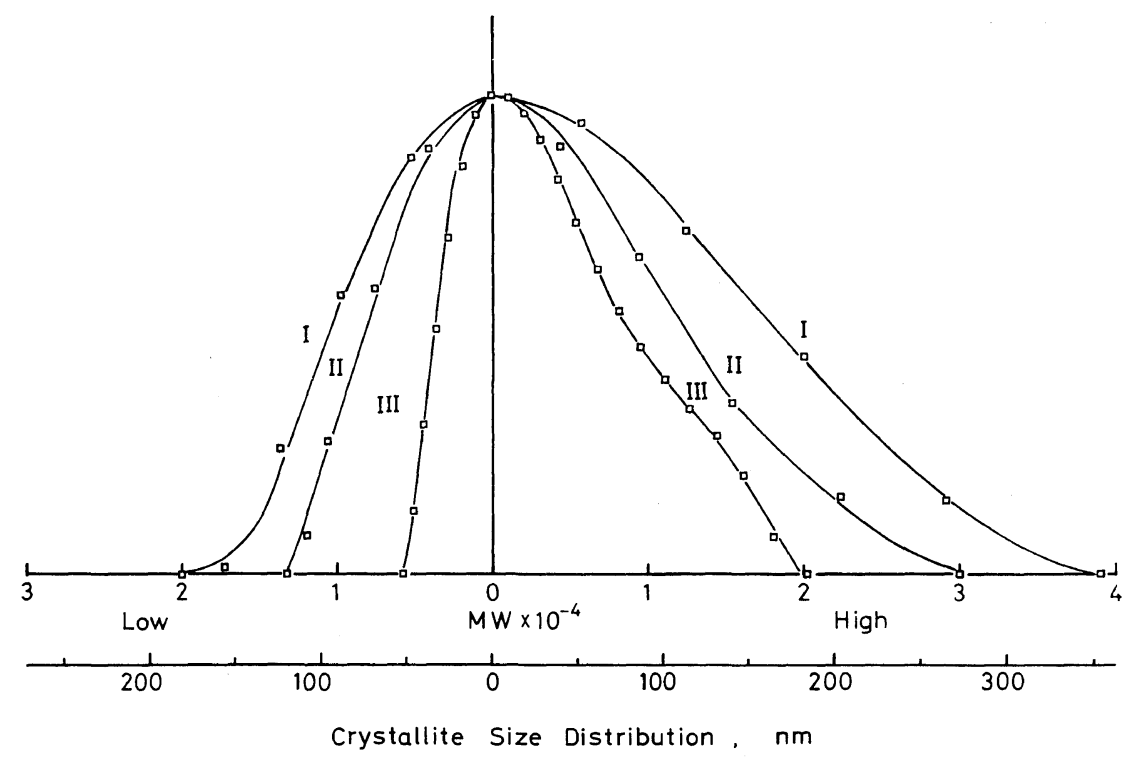

Figure 18. Degradation time dependence of MWD corresponding to the lamellar thickness distribution of ordinary ECC formed by cooling from the melt at $305 \mathrm{MPa}$ : I, $8 \mathrm{~h}$; II, $24 \mathrm{~h}$; III, $48 \mathrm{~h}$.

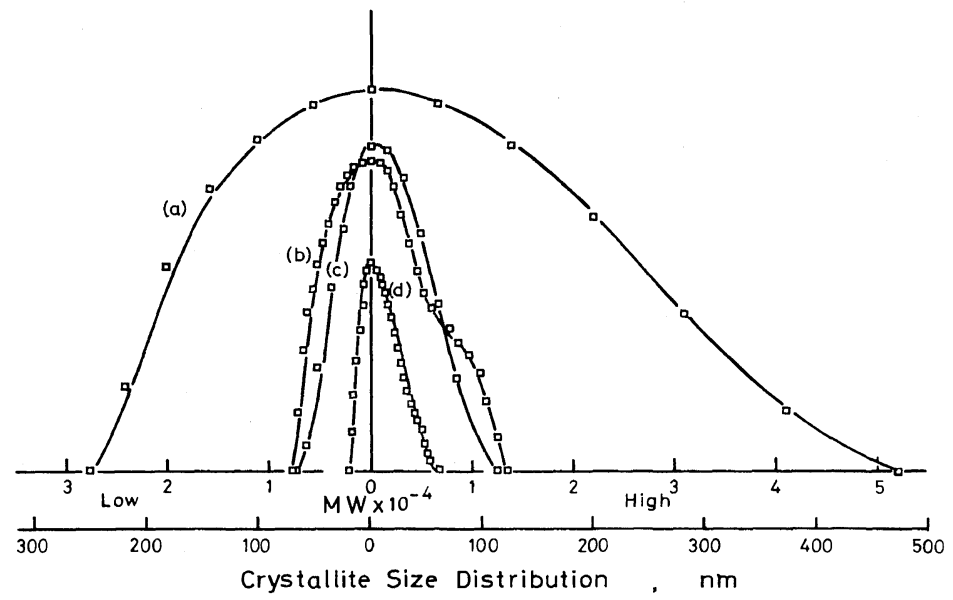

Figure 19. Variation in the lamellar thickness distribution of ordinary ECC with crystallization temperature. Samples were degraded for $48 \mathrm{~h}$ : (a) $473 \mathrm{~K}$, (b) $468 \mathrm{~K}$, (c) cooled, and (d) $458 \mathrm{~K}$.

that the lamellar thickness of ordinary ECC decreased considerably with degradation time in a manner similar to that mentioned above. In this case, the lamellar thickness of FCC also decreased with degradation time. The decrease in chain length was about $73 \mathrm{~nm}$ for ordinary ECC and about $31 \mathrm{~nm}$ for FCC. At the same time, the MWD curves of the peaks narrowed greatly with degradation time. Figure 18 shows the degradation time de- pendence of the MWD having the lamellar thickness distribution of ordinary ECC. The MWD curve of the ordinary ECC degraded for $48 \mathrm{~h}$ indicated that the crystal lamellae were distributed from $186 \mathrm{~nm}$ to $370 \mathrm{~nm}$ with an average lamellar thickness of $262 \mathrm{~nm}$. Figure 19 shows a comparison of the MWD curves for various ordinary ECC sample degraded for $48 \mathrm{~h}$. The lamellar thickness distribution of ordinary ECC broadened greatly with crystalli- 


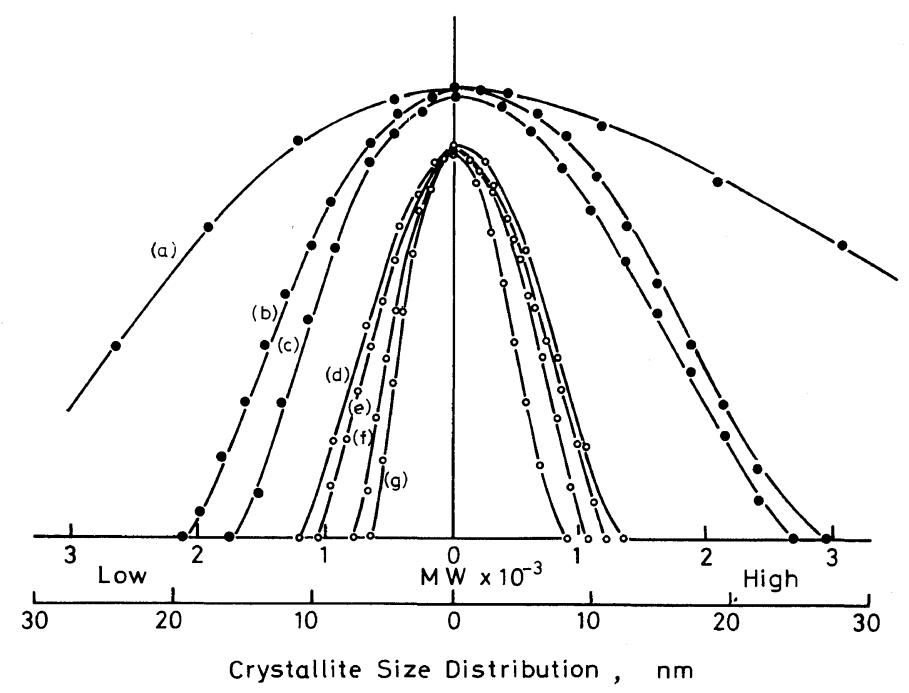

Figure 20. Variation in lamellar thickness distributions of thick FCC (O) and thin FCC (O) with crystallization temperature. (a), (b), and (c) are the distributions of thick FCC formed at $473 \mathrm{~K}$ and 305 $\mathrm{MPa}, 468 \mathrm{~K}$ and $305 \mathrm{MPa}$, and $434 \mathrm{~K}$ and $106 \mathrm{MPa}$, respectively. (d), (e), (f), and (g) are the distributions of thin FCC formed at $473 \mathrm{~K}, 458 \mathrm{~K}$, by cooling from the melt under $305 \mathrm{MPa}$, and $423 \mathrm{~K}$ under $106 \mathrm{MPa}$, respectively.

Table I. Parameters for corrected MWD peaks corresponding to crystal thickness distributions of crystals from the various samples

\begin{tabular}{|c|c|c|c|c|c|c|c|c|c|c|}
\hline \multicolumn{3}{|c|}{ Crystallization } & \multirow{3}{*}{$\begin{array}{c}\text { Acid } \\
\text { treatment } \\
\text { at } 353 \mathrm{~K}\end{array}$} & \multirow{2}{*}{\multicolumn{2}{|c|}{ Crystal }} & \multirow{3}{*}{$\begin{array}{r}L_{\text {peak }} \\
\mathrm{nm}\end{array}$} & \multirow{3}{*}{$\frac{\text { Half width }}{n m}$} & \multirow{3}{*}{$\begin{array}{c}\begin{array}{c}\text { Whole } \\
\text { distribution }\end{array} \\
\mathrm{nm}\end{array}$} & \multirow{3}{*}{$L_{\max } / L_{\min }$} & \multirow{3}{*}{$M_{w} / M_{1}$} \\
\hline \multirow{2}{*}{$\frac{\text { Pressure }}{\mathrm{MPa}}$} & \multirow{2}{*}{$\frac{\text { Temp }}{\mathrm{K}}$} & \multirow{2}{*}{$\frac{\text { Time }}{h}$} & & & & & & & & \\
\hline & & & & & & & & & & \\
\hline \multirow[t]{4}{*}{106} & 423 & 20 & 48 & & FCC & 33.5 & 12 & $26-45$ & 1.73 & $1.01_{2}$ \\
\hline & 434 & 20 & 40 & Thick & FCC & 92 & 25 & $75-116$ & 1.55 & $1.00_{8}$ \\
\hline & & & & & FCC & 41 & 12 & $30-50$ & 1.67 & $1.01_{0}$ \\
\hline & $\mathrm{CoO}$ & & 48 & & $\mathrm{FCC}$ & 31 & 9 & $25-39$ & 1.56 & $1.00_{8}$ \\
\hline \multirow[t]{10}{*}{305} & 458 & 20 & 48 & Ordinary & ECC & 103 & 42 & $84-148$ & 1.76 & $1.01_{9}$ \\
\hline & & & & & FCC & 43 & 12.5 & $33-52$ & 1.58 & $1.00_{9}$ \\
\hline & 468 & 20 & 48 & Ordinary & $\mathrm{ECC}$ & 230 & 111 & $159-350$ & 2.20 & $1.03_{2}$ \\
\hline & & & & Thick & FCC & 72 & 28.5 & $52-99$ & 1.90 & $1.01_{5}$ \\
\hline & & & 24 & Thin & FCC & 25 & 11.5 & $16-31$ & 1.94 & $1.02_{4}$ \\
\hline & 473 & 20 & 24 & Ordinary & $\mathrm{ECC}$ & 678 & 507 & $284-1240$ & 4.37 & $1.11_{1}$ \\
\hline & & & & Thick & FCC & 115 & 44 & $82-150$ & 1.83 & $1.01_{6}$ \\
\hline & & & & Thin & FCC & 52 & 27 & $38-82$ & 2.16 & $1.02_{4}$ \\
\hline & $\mathrm{CoO}$ & & 48 & Ordinary & $\mathrm{ECC}$ & 262 & 103 & $186-370$ & 1.99 & $1.05_{6}$ \\
\hline & & & & & $\mathrm{FCC}$ & 26 & 9 & $20-36$ & 1.80 & $1.0 \mathrm{I}_{4}$ \\
\hline
\end{tabular}

zation temperature. The MWD of ordinary ECC formed at $458 \mathrm{~K}$ was comparable to the MWD of thick FCC. The MWD of the ordinary ECC formed at $473 \mathrm{~K}$ was distributed from $284 \mathrm{~nm}$ to $1.24 \mu \mathrm{m}$, and had an average lamellar thickness of $678 \mathrm{~nm}$.
The MWD is comparable to the MWD of high ECC formed under $500 \mathrm{MPa}$.

Figure 20 shows a comparison of the MWDs of thick FCC and thin FCC in various samples formed at $106 \mathrm{MPa}$ and $305 \mathrm{MPa}$. The MWD curves of thin 
FCC are very similar to each other, irrespective of the crystallization condition, with distributions being approximately symmetric at average lamellar thicknesses. On the other hand, the MWD curves of thick FCC were asymmetric and tailed to longer chain lengths. The lamellar thickness distributions of thick FCCs were approximately twice those of thin FCCs.

Table I summarizes the data on average lamellar thickness and size distribution in the molecular chain direction of the various kinds of crystals of ordinary ECC, thick FCC, and thin FCC, crystallized under $106 \mathrm{MPa}$ and $305 \mathrm{MPa}$. The peak chain length $L_{\text {peak }}$ indicates average lamellar thickness of each crystal. The half width, the whole distribution, the polydispersity $M_{w} / M_{n}$, and the ratio of maximum to minimum chain length $L_{\max } / L_{\min }$ for each MWD peak give information on the lamellar thickness distribution of each crystal. The values of $M_{w} / M_{n}$ for all FCCs and thick FCCs were less than 1.03 , while the values for ordinary ECC were as much as 1.10. Also the $L_{\max } / L_{\min }$ values for the FCCs were less than 2.0, while the values for the ordinary ECCs increased from 1.7 to 4.4 with increasing average crystal thickness. This information indicates that the lamellar thickness distribution of ordinary ECC broadens with an increase in the average lamellar thickness of the crystal.

\section{DISCUSSION}

Ward and Williams ${ }^{7}$ demonstrated with various FCC crystals of polyethylene that the degree of degradation can be expressed in a physically meaningful way in terms of the GPC final peak intensity $P_{1}$, instead of degradation time. Strict application of their method is able only to a single component system consisting of FCC. In comparison, the peak chain length of the FCC shown in Figure 2 was replotted in Figure 21 as a function of the weight fraction of the final peak intensity $P_{1}$ which indicates the MWD peak of the single chain traverse length of FCC. The average lamellar thickness of the original FCC was extrapolated to be approximately $39 \mathrm{~nm}$, which is slightly different from the value estimated by extrapolation to zero degradation time. Generally speaking, it was actually impossible to apply strictly their method on the pressure-crystallized polyethylenes consisting of several kinds of crystals with different lamellar

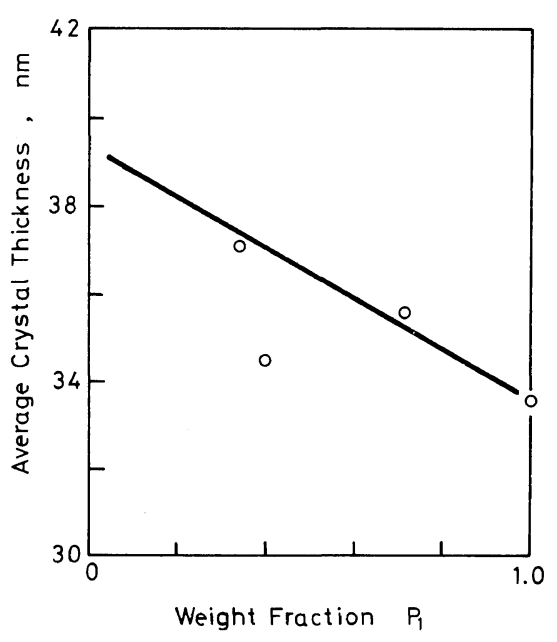

Figure 21. Variation in the average crystal thickness of FCC formed at $423 \mathrm{~K}$ as a function of the weight fraction of the final peak intensity $P_{1}$ which corresponds to the single chain traverse length of the FCC.

thicknesses and different morphological structures. Multi-component systems such as (1) thin FCC and thick FCC in a sample, (2) FCC and ordinary ECC in a sample, and (3) thin FCC, thick FCC, and ordinary ECC in a sample were used in this study. Accordingly, the average lamellar thickness of each original crystal was estimated approximately by extrapolation as a function of degradation time to zero time.

The temperature dependence of the average lamellar thicknesses of all crystals formed at 305 MPa had an upward curvature, typical of polymer crystallization under more usual circumstances. It should be noted in particular that the lamellar thickness of ordinary ECC increased steeply with crystallization temperature in the region between $458 \mathrm{~K}$ and $473 \mathrm{~K}$. Furthermore, interesting relations could be found concerning average lamellar thicknesses of different crystals in the same samples. Also in this study, it was shown that the average lamellar thickness of FCC was often about one tenth the average lamellar thickness of ordinary ECC in the same degraded samples. The average lamellar thickness of thick FCC was often found to be about twice the average thickness of thin FCC in the same sample, but the ratio tended to increase to about three times as much at higher crystallization temperatures. 
In regard to the lamellar thickness distributions of the so-called ECC, only a rough estimation was made on the basis of fracture surface observation..$^{8,9}$ Recently, Bassett et al. ${ }^{10}$ made a comparison of results on lamellar thickness distribution obtained by the fracture surface observation with those obtained by GPC analysis of the MWD of crystals degraded with fuming nitric acid. These results showed qualitatively good agreement, but a precise analysis of the observed GPC curves was not performed. In this paper, the accurate information has been obtained by correcting the observed GPC curves for instrumental spreading, using ChangHuang's method. We generally succeeded making correction for instrumental spreading on the observed GPC curves, except for a number of insignificant cases. The calculated results in this study suggest that the precision might be scattered depending on the shape and complexity of the GPC curve. For example, the results were unexpectedly at variance with an accurate correction on the GPC curves having narrow, single MWD peaks as shown in Figure 2 (d) and Figure 7 (d). Also, as to the complex curve with the multiple GPC peaks as shown in Figure 13, the spreading correction was likewise difficult. On the other hand, it was often found that a small peak observed at the ends of a GPC curve was corrected with the result that the MWD peak was too large, as shown in Figures 3(c)-(d) and Figures 9(b)-(f). The corrected GPC curves often diverged at the ends of the GPC curves. The cause for this may be due to the sensitive correction from the raw GPC curves of low precision. The spreading correction on GPC curves of the degraded polyethylenes was performed going on the two assumptions of the Gaussian spreading, and the constant value of resolution factor $h=1.3$. The low precision may be partly due to the uncertainty of the assumptions. Taking into account these results, the application of ChangHuang's correction method should be strictly limited in view of the accurate quantitative analysis of spreading correction. But at least, the spreading corrections performed in this series seem acceptable semiquantitatively.

Whole distributions for the lamellar thickness of the FCCs were almost constant at about $20 \mathrm{~nm}$, and all the distributions for the thick FCCs were from about 40 to $50 \mathrm{~nm}$, except for the value of thick FCC formed at $473 \mathrm{~K}$. On the other hand, all the distributions for the lamellar thickness of ordinary ECCs were usually from about 200 to $250 \mathrm{~nm}$, except for the extremely large value of about $700 \mathrm{~nm}$ for ordinary ECC formed at $473 \mathrm{~K}$. An interesting feature of the lamellar thickness distribution of ordinary ECC is that the MWD curves were asymmetric at the average lamellar thicknesses and that the crystal lamellae were distributed extensively toward longer chain lengths as illustrated in Figure 19.

It is noteworthy that the average lamellar thickness of ordinary ECC decreased considerably with degradation time. As shown in Figure 12, Figure 14, and Figure 17, the decrease in the chain length of ordinary ECC varied from $60 \mathrm{~nm}$ to about $110 \mathrm{~nm}$ during the $48 \mathrm{~h}$ degradation, and the thinning of lamellar chains in ordinary ECC tended to become greater with an increase in the average lamellar thickness. In addition, it became quite clear that the chain cutting of polymer chains did not occur to the same degree on all ordinary ECCs, but took place more vigorously on crystals with thick lamellae than on crystals with thin lamellae. This indicates that the surface structure of ordinary ECC is easily accessible to nitric acid etching and that crystals with thick lamellae are more accessible to nitric acid etching.

It is very interesting to note the degradation time depenence of the higher-order peaks which correspond to integral multiple the chain traverse length of crystals. Since the appearance of higherorder peaks are characteristic of folded-chain structure, the behavior of the peaks provides information on folds in the crystal surfaces. The higher-order peaks in Figure 2 and Figure 7 which corresponded to double or triple the chain traverse length of the FCCs reduced markedly during the $48 \mathrm{~h}$ degradation. On the other hand, the 2nd-order peak corresponding to double the chain traverse length of the thick FCC in Figure 3 remained even after the drastic $72 \mathrm{~h}$ degradation. This fact suggests that folds are distributed widely beneath the crystal surfaces of thick FCC, i.e., "burried" folds may exist beneath the crystal sufaces which were suggested by Keller et al. ${ }^{11}$ The corrected GPC curves of the samples formed at $458 \mathrm{~K}$ and $468 \mathrm{~K}$ in Figures 9 and 11 indicated the existence of the higher-order peaks corresponding to twice and quadruple the chain traverse length of ordinary ECC. This indicates clearly that remarkable numbers of folds 
are contained in the crystal surfaces of ordinary ECC. In these cases, the peaks remained even after the $48 \mathrm{~h}$ degradation. On the other hand, the higherorder peaks for ordinary ECC formed at $473 \mathrm{~K}^{\circ}$ disappeared in the initial stage of oxidation as shown in Figure 13. The similar behavior of the higher-order peaks was observed on the ordinary ECC formed by cooling from the melt as shown in Figure 16. These behaviors of higher-order peaks may reflect sensitively the difference in surface structure of each ordinary ECC. The rapid disappearance of higher-order peaks of ordinary ECC in the above cases suggests that folds are nearly absent or are present to a small extent on crystal surfaces. Since the average lamellar thickness of ordinary ECC in these cases are more than about $300 \mathrm{~nm}$ and comparable to the number-average $\mathrm{MW}$ of the original material, the crystal lamellae of ordinary ECC will terminate in the extended-chains. The unusually large effect of chain cutting of ordinary ECCs may be reduced not only in the amorphous layers between crystallites, but also reduced in the crystalline lamellae beneath crystal surfaces. But at this stage, the contributions of the amorphous chains and the crystalline chains cut with nitric acid cannot be estimated separately.

Taking into account these observations, it seems reasonable to consider ordinary ECC with gradually disordered, long surface layers of 20-50 nanometers, as a possible model. The possibility of such long surface layers in the neighborhood of the crystal surfaces of ordinary ECC may probably be related closely to the ease of occurrence of the hexagonal modification of polyethylene under high pressure and high temperature. ${ }^{12}$

In the initial and intermediate stages of oxidation, a small peak could often be observed clearly in the lowest MW region on the GPC curves. This peak has neither been reported by GPC nor by fracture surface observation up to now. During the drastic degradation, this small peak disappeared in some cases, as shown in Figure 2, Figure 7, Figure 11, and
Figure 16, but remained in other cases, as shown in Figure 3, Figure 9, and Figure 13. The strong resistivity against oxidation suggests that this peak may be attributed to the MWD having a lamellar thickness distribution of the metastable very thin FCC with an average thickness of about $9-16 \mathrm{~nm}$. This GPC peak corresponds to the low-temperature endothermic peak observed often at about $401 \mathrm{~K}$ or below on the DSC melting curves.

Acknowledgement. The authors wish to express their gratitude to Professor R. Y. M. Huang of the University of Waterloo who kindly permitted us to use the computer program for calculating actual molecular weight distribution of polymers from observed GPC curves. The authors also wish to thank Dr. Y. Tanabe for his helpful suggestions in making the calculations.

\section{REFERENCES}

1. Y. Maeda and H. Kanetsuna, Polym. J., 13, 357 (1981).

2. Y. Maeda and H. Kanetsuna, J. Polym. Sci., Polym. Phys. Ed., 12, 2551 (1974).

3. K. S. Chang and R. Y. M. Huang, J. Appl. Polym. Sci., 13, 1459 (1969).

4. T. Williams, D. J. Blundell, A. Keller, and I. M. Ward, J. Polym. Sci., A-2, 6, 1613 (1968).

5. T. Williams, A. Keller, and I. M. Ward, J. Polym. Sci., A-2, 6, 1621 (1968).

6. I. M. Ward and T. Williams, J. Mácromol Sci., Phys., B5, 693 (1971).

7. I. M. Ward and T. Williams, J. Polym. Sci., A-2, 7, 1585 (1969).

8. R. B. Prime and B. Wunderlich, J. Polym. Sci., A-2, 7, 2061 (1969).

9. D. V. Rees and D. C. Bassett, J. Polym. Sci., A-2, 9, 385 (1971).

10. D. C. Bassett, B. A. Khalifa, and R. H. Olley, $J$. Polym. Sci., Polym. Phys. Ed., 15, 995 (1977).

11. A. Keller, E. Martuscelli, D. J. Priest, and Y. Udagawa, J. Polym. Sci., A-2, 9, 1807 (1971).

12. K. Takamizawa, Y. Urabe, and H. Hasegawa, Polym. Prepr., Jpn., 28, (9) 1854 (1979). 